doi:10.4149/neo_2015_010

\title{
Overexpression of Survivin mutant Thr34Ala induces apoptosis and inhibits gastric cancer growth
}

\author{
S. C. DANG*, S. FENG, P. J. WANG, L. CUI, J. G. QU, J. X. ZHANG \\ Department of General Surgery, the Affliated Hospital of Jiangsu University, Zhenjiang 212001, Jiangsu Province, China \\ *Correspondence: dscgu@163.com
}

Received November 13, 2014 / Accepted July 14, 2014

\begin{abstract}
Survivin is highly expressed in human gastric cancer cells and correlated with chemoresistance and poor prognosis. In this study, we explored the effect of adeno-associated virus (AAV)-mediated survivin dominant mutant Thr34Ala (rAAV-SurMut(T34A)) on gastric cancer growth. AAV-Sur-Mut (T34A) virus was generated and purified using the AAV vector pAM/ CAG-WPRE.poly(A) vector. Cell proliferation was determined by the 3-(4,5-Dimethylthiazol-2-yl)-2,5-Diphenyltetrazolium Bromide (MTT) Assay. Apoptosis was determined by Flow cytometry and Terminal deoxynucleotidyl transferase dUTP nick end labeling. Gene expression was determined by Western blot and immunohistochemistry. Tumor growth was evaluated using a xenograft mouse model. Overexpression of survivin promoted cell growth of gastric cancer cells. Infection of rAAVSur-Mut(T34A) virus inhibited cell proliferation, induced apoptosis and sensitized gastric cancer cells to 5-Fluorouracil in vitro. Treatment of rAAV-Sur-Mut(T34A) significantly inhibited cell proliferation, induced apoptosis and inhibited gastric cancer growth in vivo. Our results suggest that the combination of rAAV-Sur-Mut(T34A) and chemotherapy may be a new approach for gastric cancer therapy.
\end{abstract}

Key words: Survivin, survivin mutant T34A, adeno-associated virus, gastric cancer, apoptosis, gene therapy

Survivin, a member of inhibitor of apoptosis (IAP) gene family, is expressed during embryonic and fetal development, although it is completely down-regulated in terminally differentiated adult tissues $[1,2]$. Survivin is highly expressed in several common cancer site $[3,4]$. Overexpression of survivin inhibits apoptosis induced by various stimuli $[1,5]$. It has been reported that survivin levels in cancer cells are critically regulated by phosphorylation on Thr34 [6]. Protein phosphorylation is known to regulate cell death pathways and cytoprotection [7]. In the survivin crystal structure, Thr34 is ideally positioned in an acidic knuckle to regulate the binding of potential client proteins controlling survivin stability and/or ubiquitin-dependent degradation [8]. Ubiquitin-dependent proteasome destruction has been recognized as a critical mechanism to regulate protein levels, influencing survivin-dependent cytoprotection [9]. Thus, overexpression of nonphosphorylatable survivin mutant (T34A) may abolish kinase $\mathrm{p} 34^{\mathrm{cdc} 2}$-cyclin $\mathrm{B} 1$ on the survivin phosphorylation,

Abbreviations: Adeno-associated virus, AAV; Survivin mutant Thr34Ala, Sur-Mut(T34A); 5-Fluorouracil, 5-FU; subcutaneously, s.c. resulting in the ubiquitin-dependent degradation of survivin [10]. Studies have shown that plasmids- or a adenovirusmediated expression of survivin mutant T34A increased the sensitivity to apoptosis in response to chemotherapeutic drugs and inhibited tumor growth in vivo, indicating that survivin mutant $\mathrm{T} 34 \mathrm{~A}$ is a promising target for cancer therapy [11-14].

Stomach cancer is one of the most common malignant tumors in the world and fourth leading cause of cancer-related death. While the early diagnosis of gastric cancer has made great progress and early stage gastric cancers can be successfully treated by surgery, however, advanced stage gastric cancer can not be cured by surgery and the combination chemotherapy. Thus, new strategies, such as those that target apoptosis, are required to improve the prognosis of gastric cancer patient mortality worldwide. It has been demonstrated that human gastric cancer cells and tissues express high levels of survivin $[4,15]$. Survivin expression is correlated with shorter survival rate in patients with gastric cancer [15-17]. Previous study has shown that targeting inhibition of survivin could suppress gastric tumorigenicity and angiogenesis [18]. Therefore, targeting 
inhibition of survivin expression and function may be a new strategy for gastric cancer gene therapy [19].

While adenoviral-mediated Survivin mutant (T34A) has been shown to exhibit promising anti-tumor effects in several cancer models $[11,20]$, adenoviral-mediated gene transfer may cause a host immune response to the transduced target cells. Adeno-associated virus (AAV) is a small virus that infects both dividing and non-dividing cells [21]. AAV is not currently known to cause disease [21]. Furthermore, AAV vectors infiltrate human solid tumor tissue in vivo more effectively than adenoviral vectors [22]. These features make AAV a very attractive vector for gene therapy. A previous study has demonstrated that AAV mediated-Sur-Mut induced cell apoptosis and inhibited tumor growth in colon cancer in vivo [23]. However, the effect of AAV-mediated survivin mutant T34A on human gastric cancer growth is unknown. In the present study, we have investigated the therapeutic effect of AAV-mediated survivin mutant (T34A) on human gastric cancer growth. Our results for the first time show that AAVmediated survivin-Mutant (T34A) (AAV-Sur-Mut(T34A)) could induce apoptosis, inhibit cell proliferation and inhibit tumor growth in gastric cancer.

\section{Material and methods}

Cell culture and chemicals. Human gastric cancer cell lines SGC7901 (Shanghai Biochemical Institute of China ${ }^{23}$ ) and AGS (ATCC, Rockville, MD, USA) were maintained in RPMI-1640 containing 10\% fetal bovine serum (FBS), $100 \mathrm{U} / \mathrm{ml}^{-1}$ penicillin, $100 \mu \mathrm{g} \mathrm{ml}^{-1}$ streptomycin (Gibco BRL, Life Technologies, NY, USA). 5-Fluorouracil (5-FU, $10 \mu \mathrm{g} / \mathrm{ml}$, Sigma, USA) were dissolved in sterilized water and stored at $4{ }^{\circ} \mathrm{C}$.

Generation of Sur-Mut(T34) plasmid. The reversetranscriptase polymerase chain reaction (RT-PCR) was used to generate pcDNA3-survivin plasmid and an overlap extension PCR was used to construct pcDNA3-Sur-Mut(T34A) plasmids as previously described [18]. The T34A mutation was introduced into pcDNA3-survivin cDNA by using the oligonucleotide 5'-GGCTGCGCCTG CgCCCCGGAGCGGATG-3'. All of the constructs were confirmed by sequencing.

Establishment of AGS and SGC7901 stable transfectants expressing survivin. AGS and SGC7901 cells were seeded into 6 -well plates $\left(2.5 \times 10^{5}\right.$ cells/well $) 24$ hours before transfection. The cells were transfected with $4 \mu \mathrm{g} /$ well of pcDNA3 empty vector and pcDNA3-survivin plasmid using LipofectAMINE 2000 (Life Technologies, Inc., Grand Island, NY) according to the manufacturer's instructions. Forty-eight hours after transfection, the cells were passaged at 1:20 (v/v) and cultured in medium supplemented with Geneticin (G418) at $0.8 \mathrm{mg} / \mathrm{ml}$ for 4 weeks. Stably transfected clones were picked and the overexpression of survivin in stable transfectants were confirmed by Western blots. The stable transfectants were maintained in RMPI containing $200 \mu \mathrm{g} / \mathrm{ml} \mathrm{G} 418$ for further studies.
Construction and generation of recombinant AAV-SurMut(T34A) virus. A recombinant AAV plasmid encoding Sur-Mut(T34A) was constructed according to method previously described [23]. Briefly, full-length Sur-Mut(T34A) cDNA was cut with XhoI and BamHI from pcDNA3-SurMut(T34A) and subcloned into the corresponding XhoI and BamHI sites of pAM/CAG-WPRE-BGHpolyA to produce pAM/CAG-Sur-Mut(T34A) plasmid. pAM/CAG-SurMut(T34A) plasmid was transfected into HEK293T cells to generated recombinant $\mathrm{AAV}$ virus. AAV virus was purified by HiTrap Heparin column chromatography (Sigma Chemical Co., St. Louis, MO). The AAV viral genome titer was quantified by real-time PCR using TaqMan (Perkin-Elmer Biosystems, Foster City, CA).

Assay of Anchorage-dependent cell growth. The AGS-Sur and SGC7901-Sur stable transfectants and control stable transfectants $\left(5 \times 10^{4}\right)$ were seeded into 6-well plates. Cells from triplicate wells were collected every other day. Cell numbers were determined using a Coulter counter (Coulter Electronics, Miami, FL). The number of cells is reported as the means \pm $\mathrm{SD}$ at the indicated days after plating.

3-(4,5-Dimethylthiazol-2-yl)-2,5-Diphenyltetrazolium Bromide (MTT) assay. Cell proliferation was determined by MTT assay [18]. AGS and SGC7901 cells $\left(1 \times 10^{4}\right)$ were plated into 96-well plates. After twenty-four hours, cells were infected with different doses of AAV virus for 96 hours. Twenty $\mu \mathrm{l}$ of MTT stock solution $(5 \mathrm{mg} / \mathrm{ml})$ was added to each well and further incubated at $37^{\circ} \mathrm{C}$ for 3 hours. DMSO was added to dissolve formazan production. The absorbance at wavelength $595 \mathrm{~nm}$ was measured with a micro-ELISA reader (Bio-Rad, Hercules, CA). The ratio of the absorbance of treated cells relative to that of the control cells (Untreated group) was calculated and expressed as a percentage of cell proliferation.

Flow cytometry. Gastric cancer cells were collected after treatment. Cells were fixed in ice-cold $70 \%$ ethanol in PBS and stored at $-20^{\circ} \mathrm{C}$ before use. After resuspension, cells were washed and incubated with $100 \mu \mathrm{l}$ of RNase I $(1 \mathrm{mg} / \mathrm{ml})$ and $100 \mu \mathrm{l}$ of propidium iodide $(400 \mu \mathrm{g} / \mathrm{ml}$; Sigma $)$ at $37^{\circ} \mathrm{C}$ for 30 min. Cells samples were analyzed by flow cytometry (Coulter, Luton). The cell-cycle phase distribution was calculated from the resultant DNA histogram using Multicycle AV software (Phoenix Flow Systems, San Diego, CA). Cells with subdiploid DNA content were considered apoptotic cells.

Western blot analysis. Gastric cancer cells were lysed in lysis buffer. ${ }^{23}$ Proteins were electrophoresed on $10 \%$ denaturing sodium dodecylsulfate gel and transferred to Immobilon-P membrane (Millipore, Bedford, MA). The blots were incubated with specific primary antibodies, reacted with a peroxidaseconjugated second antibody (Santa Cruz, CA) and then visualized by enhanced chemiluminescence (ECL, Amersham, Piscataway, NJ). Rabbit survivin (71G4B7) monoclonal antibodies were purchased from Cell Signaling (Danvers, MA), p-survivin (Thr34)-R antibody, caspase 3, XIAP, c-IAP1, cIAP2, cytochrome $c$ and $\beta$-actin monoclonal antibodies were all from Santa Cruz (Santa Cruz, CA). 
Immunohistochemistry (IHC). Tumor tissue sections $(4 \mu \mathrm{m})$ were deparaffinized in xylene and rehydrated in graded ethanol. Antigen retrieval was conducted by immersing sections in citrate buffer and microwaving for a total of $10 \mathrm{~min}$. Endogenous peroxidase activity was quenched by $3 \% \mathrm{H}_{2} \mathrm{O}_{2}$ for $10 \mathrm{~min}$. After blocked with $10 \%$ normal goat serum, the sections were incubated with primary rabbit anti-Ki67 antibodies (Abcam, Cambridge, MA) at $4{ }^{\circ} \mathrm{C}$ overnight and then incubated with peroxidase-labeled goat anti-rabbit antibodies (Dako Cytomation, Copenhagen, Denmark). In each experiment, a negative control was included in which the primary antibody was replaced by rabbit IgG. The negative control sections showed not unspecific immunoreactivity. The number of Ki-67 cells was assessed in 10 randomly selected fields of each slide viewed at $\times 400$ magnification. The percentage of Ki-67 was calculated as the number of Ki-67-positive cells/ total number of nucleated cells $\times 100 \%$. Data are the mean \pm SD of the proliferative index from 9 sections of 3 animals per group.

In situ detection of apoptotic cells by terminal deoxynucleotidyl transferase dUTP nick end labeling assay. Apoptosis in xenograft tumors was determined by TUNEL staining (Zymed, San Francisco, CA) according to the production manuals. The percentage of apoptotic cells was assessed in 10 randomly selected fields viewed at $400 \times$ magnifications. The apoptotic index (A/I) was calculated as number of apoptotic cells/total number of nucleated cells $\times 100 \%$. The number of apoptotic cells was assessed in 10 randomly selected fields of each slide viewed at $\times 400$ magnification. Apoptotic index was calculated as the number of apoptotic cells/total number of nucleated cells $\times 100 \%$. Data are the mean \pm SD of the apoptotic index from 9 sections of 3 animals per group.

Gastric cancer xenograft model. Female BALB/c athymic nude mice at 6-week old were purchased from Shanghai Experimental Animals centre of Chinese Academy of Sciences. All animal studies were conducted under approved guidelines of the Animal Care and Use Committee of University. $1 \times 10^{6}$ exponentially growing SGC7901 cells were injected subcutaneously (s.c.) into the flanks. When tumors reached a size of $80 \mathrm{~mm}^{3}-100 \mathrm{~mm}^{3}$, mice were injected at 3 tumor sites with rAAV-Sur-Mut(T34A) or rAAV-Ctrl at $5 \times 10^{10}$ viral particles/ site of injection on 5 consecutive days. Tumor volume was measured weekly after injection. Tumor volumes were calculated using the following formula: $\mathrm{V}\left(\mathrm{mm}^{3}\right)=0.52 \times$ width $(\mathrm{mm})^{2} \times$ length $\left.(\mathrm{mm})\right)^{18,23}$

Statistical analysis. All experiments were repeated three times. Data are expressed as means \pm SD (standard deviations). The results were analyzed by two-tailed Student's T-test or Mann-Whitney test. $p$ value $<0.05$ was considered statistically significant.

\section{Results}

Overexpression of survivin promotes the growth in stable transfectants. We established AGS and SGC7901 stable transfectants with pcDNA3-Survivin plasmid and pcDNA3 control vector. The stable transfectants from each cell lines were selected and analyzed by Western blot. Western blot showed that the expression of survivin protein in AGS-Sur and SGC7901-Sur transfectants was obviously increased (1.6 fold and 2.1 fold, respectively) (Fig. 1A). Accordingly, AGSSur and SGC7901-Sur transfectants had significant increase in cell number compared with AGS-Ctrl and SGC7901-Ctrl transfectants 5 days after plating $(P<0.01)$. By day 7 , the number of cells was increased by $66.7 \pm 6 \%$ and $80.3 \pm 8 \%$ in AGS-Sur transfectants and SGC7901-Sur transfectants compared to their control stable transfectants (Fig. 1B-1C). These results demonstrate that overexpression of survivin promotes the growth of gastric cancer cells and suggest that survivin is important for gastric cancer cell growth.

AV-Sur-Mut(T34A) virus inhibits cell proliferation of gastric cancer cells. A previous study has shown that AAV could efficiently transduced cancer cells [23]. To investigate the effect of Sur-Mut(T34A) on gastric cancer growth, we gener-
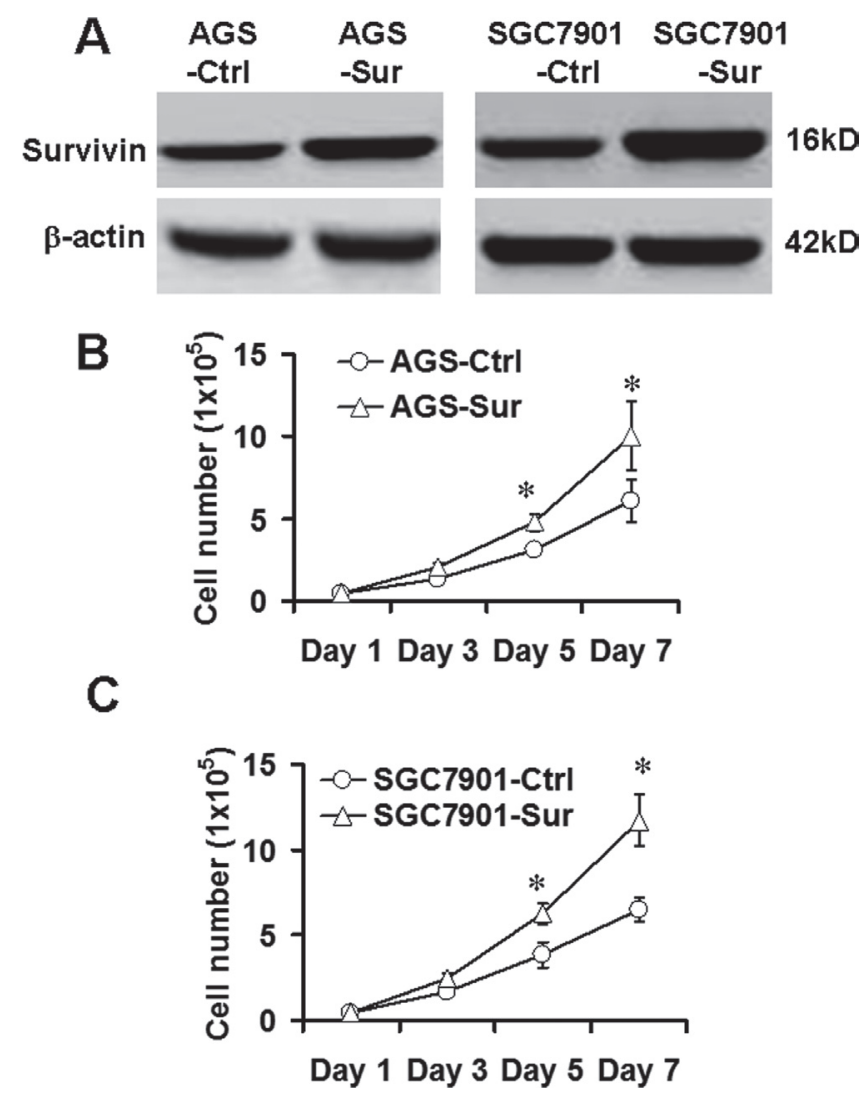

Figure 1. Overexpression of survivin promotes cell growth of gastric cancer cells. (A) Western blot showed that survivin expression was increased in AGS-Sur and SGC7901-Sur stable transfectants. The ratio of survivin to $\beta$-actin (Density) is shown. (B-C) Anchorage-dependent growth was determined in AGS-Sur stable transfectants (B) and SGC7901-Sur stable transfectants (C). Cells from triplicate wells were collected every other day. Data represent the mean \pm SD of three independent experiments. ${ }^{*} P$ $<0.01$, compared with control transfectants. 
ated rAAV-Sur-Mut(T34A) virus. The gastric cancer AGS and SGC-7901 cells were infected with the rAAV-Sur-Mut(T34A) and $\mathrm{rAAV}-\mathrm{Ctrl}$ virus efficiently expressed survivin protein (increased survivin expression assumed to reflect the cumulative levels of endogenous wild-type survivin and overexpressed dominant-negative mutant survivin) (Figure 2A, up lane). Furthermore, the expression of survivin mutant by rAAVSur-Mut(T34A) virus significantly decreased the level of endogenous Thr34-phosphorylated survivin as detected by Western Blot using antibody against phosphorylated Thr34 (p-survivin34) (Figure 2A, middle lane) in gastric cancer AGS cells, confirming that rAAV-Sur-Mut(T34A) virus efficiently transduced Sur-Mut(T34A) expression in gastric cancer cells.

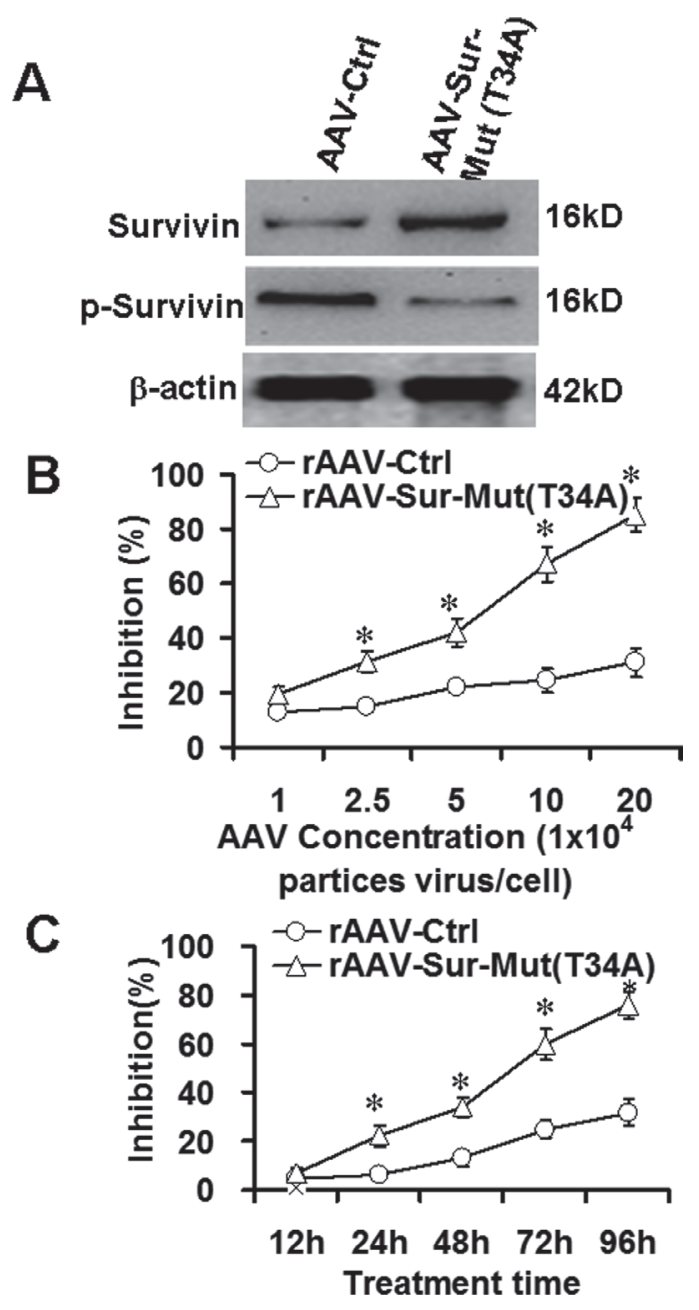

Figure 2. rAAV-Sur-Mut(T34A) inhibits expression of endogenous psurvivin and cell proliferation. (A) SGC-7901 cells were infected with rAAV virus at $1 \times 10^{5}$ viral particles/cell. Total survivin and $p$-Survivin were detected by Western blot analysis. (B-C) SGC7901 cells were seeded into 96-well plates for 24 hours. Cells were infected with the indicated doses of rAAV for 96 hours (B) or with $1 \times 10^{5}$ viral particles/ cells at the indicate time (C). Cell proliferation Western Blot was measured by MTT assay. The data are the means \pm SD of 3 independent experiments. ${ }^{*} \boldsymbol{P}<$ 0.05 , compared to rAAV-Ctrl treatment.
Consequently, the infection of rAAV-Sur-Mut(T34A) virus significantly inhibited gastric cancer cell proliferation in a dose-dependent and time-dependent manner, compared to $\mathrm{rAAV}-\mathrm{Ctrl}$ virus in gastric cancer AGS and SGC7901 cells (Figure 2B-2C).

rAAV-Sur-Mut(T34A) virus induces apoptosis of gastric cancer cells. To assess the pro-apoptotic roles of rAAV-SurMut(T34A) virus, we determined apoptosis of gastric cells infected with rAAV-Sur-Mut(T34A) and rAAV-Ctrl. Infection of rAAV-Sur-Mut(T34A) virus significantly induced apoptosis in SGC7901 and AGS cells (Figure 3A). Infection of rAAV-Sur-Mut(T34A) consistently resulted in expression of mutant survivin and several markers of apoptosis, such as caspase- 3 and the release of mitochondrial cytochrome $\mathrm{C}$ into the cytosol (Figure 3B). Survivin expression level detected by Western Blot was assumed to reflect the cumulative levels of endogenous wild-type survivin and over expressed dominant-

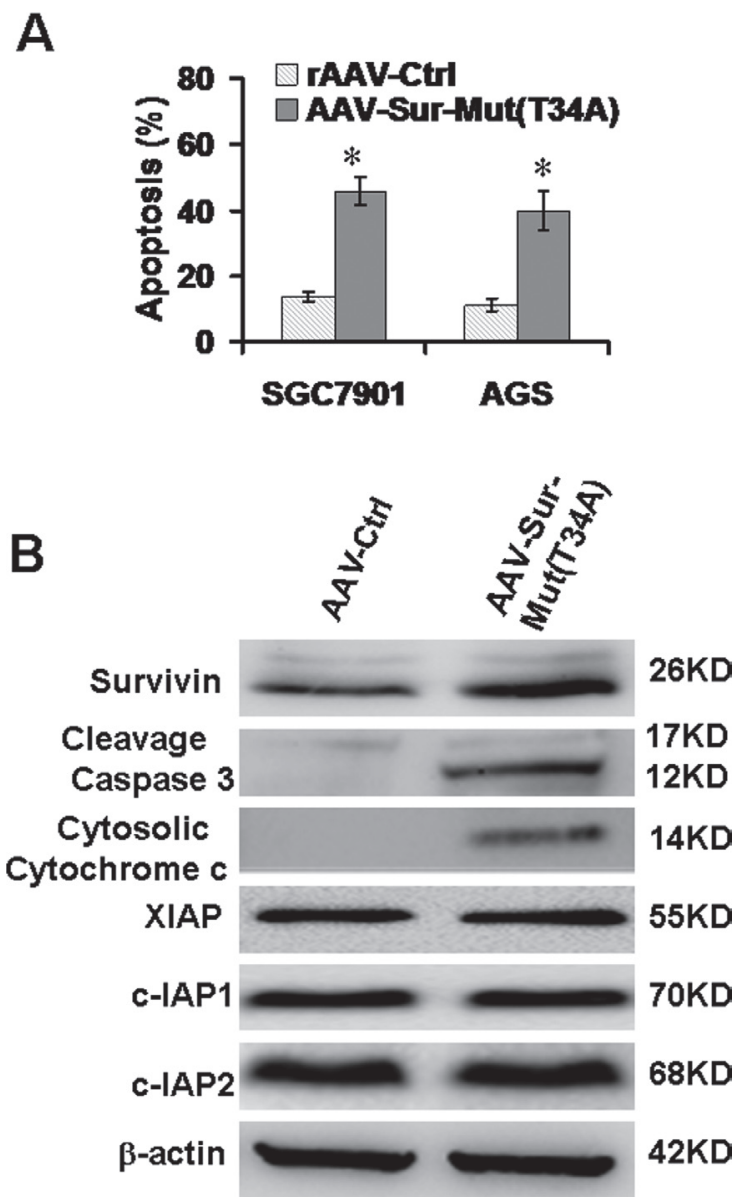

Figure 3. rAAV-Sur-Mut(T34A) induces apoptosis in gastric cancer cells. (A) SGC7-901 cells and AGS cells were infected with rAAV at $1 \times 10^{5}$ viral particles/cell. Cells were analyzed by FACS to determine the percentage of apoptosis. The data presented are means \pm SD of 3 independent experiments. ${ }^{\star} \boldsymbol{P}<0.01$, compared to $\mathrm{rAAV}$-Ctrl group. (B) Gene expression was determined by Western blots in the SGC7901 cells infected with rAAVSur-Mut(T34A) for 24 hours. 
negative mutant survivin (Figure $3 \mathrm{~B}$ ). In contrast, there was no significant change in expression of XIAP, cIAP1 and cIAP2 in gastric cancer cells infected with rAAV-Sur-Mut(T34A) (Figure 3B), suggesting that overexpression of survivin mutant dose not affect expression of other IAP members.

rAAV-Sur-Mut(T34A) sensitizes gastric cancer cells to chemotherapeutic drugs. 5-FU is the first-line chemotherapy drug for gastric cancer. We investigated whether ectopic expression of Sur-Mut(T34A) could sensitize gastric cancer cells to apoptosis induced by 5-FU. We determined the proapoptotic effect of rAAV-Sur-Mut(T34A) combined with 5-FU on gastric cancer cells. The results showed that the apoptotic rate was significantly higher in the cancer cells treated with a combination of 5-FU and rAAV-Sur-Mut(T34A) virus than in the cancer cell treated with 5-FU or rAAV-Sur-Mut(T34A) alone (Figure 4A). In contrast, Infection of rAAV-Ctrl virus did not significantly enhance 5-FU-induced apoptosis (Figure 4A). Similar results were obtained in AGS cells (Figure 4B). These results demonstrate that rAAV-Sur-Mut(T34A) sensitizes gastric cancer cells to chemotherapeutic drugs.

rAAV-Sur-Mut(T34A) inhibits tumor growth in vivo. We further investigated the effect of rAAV-Sur-Mut (T34A) on gastric cancer xenograft tumor growth. The SGC-7901

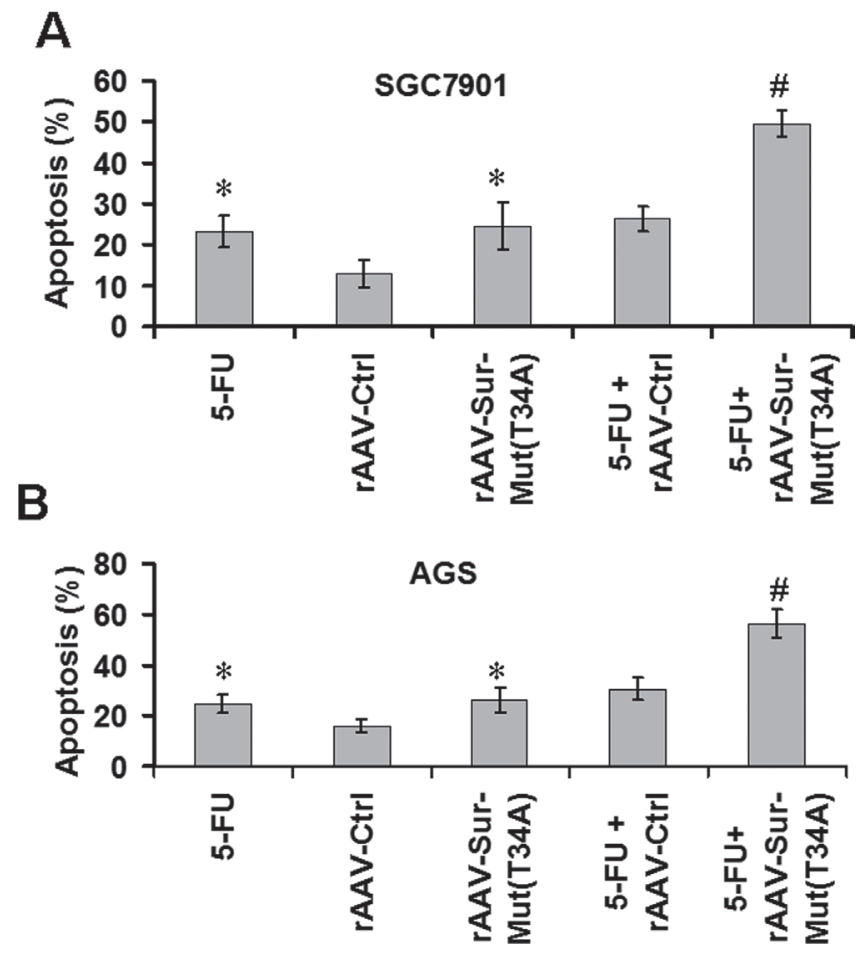

Figure 4. rAAV-Sur-Mut(T34A) Sensitizes Gastric Cancer Cells to DrugInduced Apoptosis. SGC-7901 cells (A) and AGS cells (B) were infected with $\mathrm{rAAV}$ at $1 \times 10^{5}$ viral particle/cell alone or followed by $5 \mu \mathrm{g} / \mathrm{mL}$ of 5 -FU for an additional 72 hours. Apoptosis was determined by FACS analysis. The data presented are the means \pm SD of 3 independent experiments. ${ }^{\star} P$ $<0.05$, compared to AAV-Ctrl treatment; $\# P<0.05$, compared to single treatment groups. cells were injected s.c into the flank of nude mice. When tumors reached a size of approximately $80 \mathrm{~mm}^{3}-100 \mathrm{~mm}^{3}$, the mice received the intratumor administration of rAAV-SurMut(T34A) virus. The treatment with rAAV-Sur-Mut(T34A) inhibited SGC-7901 xenograft growth by approximately $51.3 \%$ at 6 weeks post-treatment compared to rAAV-Ctrl virus treatment (Figure 5A). Similar results were obtained
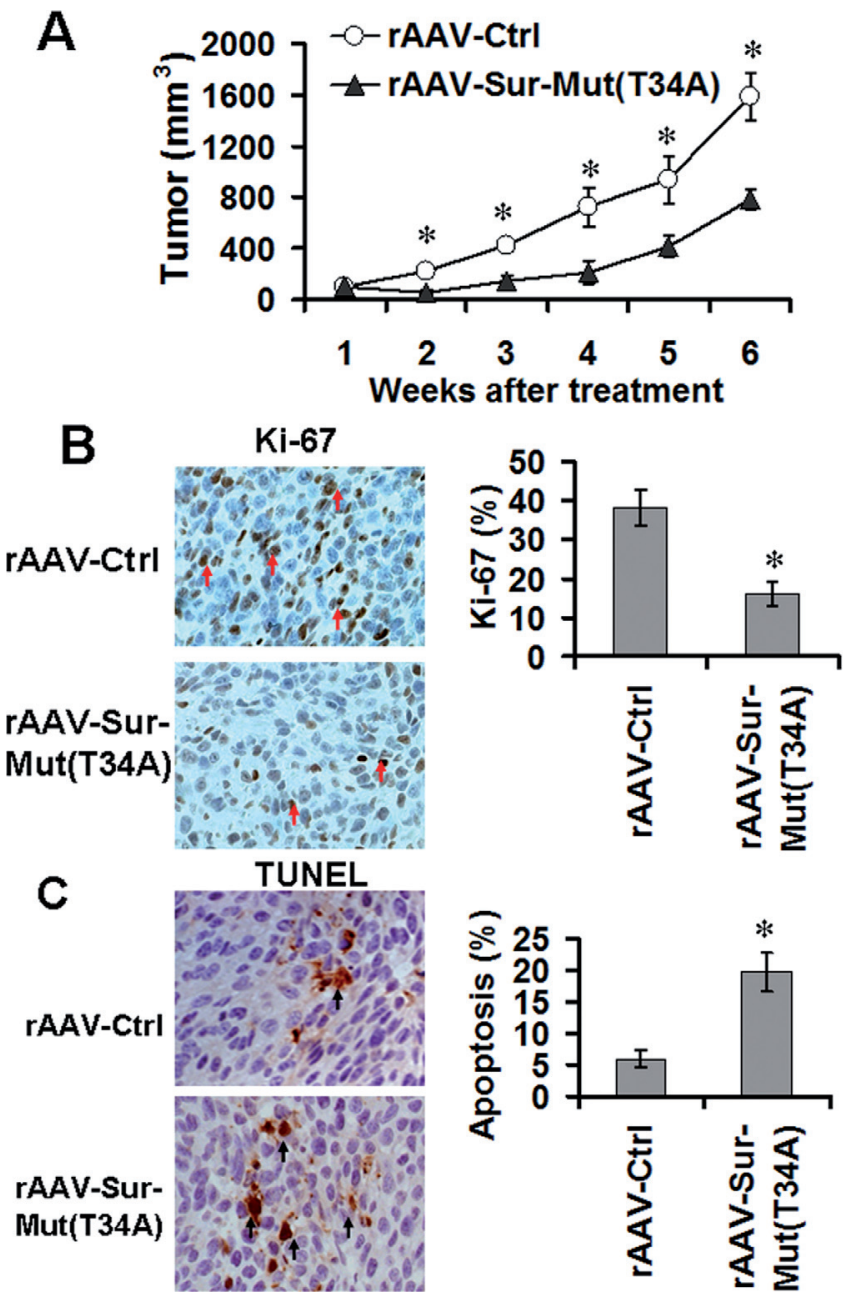

Figure 5. rAAV-Sur-Mut(T34A) inhibits tumor growth and induces apoptosis in vivo. (A) SGC-7901 cells were injected s.c. into the right flank of athymic nude mice. Masses at $80-100 \mathrm{~mm}^{3}$ volume were injected in 3 sites with rAAV-Sur-Mut(T34A) or rAAV-Ctrl at $5 \times 10^{10}$ viral particles/site of injection for 5 days. Tumor growth was measured weekly for 6 weeks. Data are the means \pm SD of tumor volume per mouse $(n=5) .{ }^{*} P<0.01$, compared to rAAV-Ctrl group. (B) Xenograft tumors tissue sections were subjected to Ki67 staining. Representative imaging of Ki-67 were shown in left panel. Arrows indicate Ki-67-positive cells. Right panel figure shows the percentages of Ki-67 cells. Data are the mean \pm SD of the apoptotic index from 9 sections of 3 animals per group. ${ }^{*} p<0.01$, compared to rAAV-Ctrl group. (C) Xenograft tumors tissue sections were subjected to TUNEL staining for detection of apoptotic cells. Representative imaging of TUNEL were shown in left panel. Arrows indicate TUNEL-positive cells. Right panel figure shows the apoptotic index. Data are the mean \pm SD of the apoptotic index from 9 sections of 3 animals per group. ${ }^{*} p<0.01$, compared to rAAV-Ctrl group. 
in AGS cells xenograft. Single intratumor administration of rAAV-Sur-Mut(T34A) inhibited AGS xenograft tumor growth by approximately $56.8 \%$ at 6 weeks compared to rAAV-Ctrl virus group. These results show that intra-tumor administration of rAAV-Sur-Mut(T34A) significantly inhibited gastric cancer growth.

rAAV-Sur-Mut(T34A) inhibits cell proliferation and induces apoptosis in vivo. We further investigated the in vivo mechanisms by which rAAV-Sur-Mut(T34A) suppressed tumor growth. Tumors injected with rAAV-Sur-Mut(T34A) virus expressed high levels of survivin mutant protein (data not shown) 36 days after injection. Consistent with enhanced expression of survivin mutant protein, Ki-67-positive cells (proliferative cells) were significantly lower in the tumors injected with rAAV-Sur-Mut(T34A) virus compared to other tumors injected with rAAV-Ctrl virus (Figure 5B). Similarly, the apoptotic cells (TUNEL-positive cells) were significantly higher in the tumors injected with rAAV-Sur-Mut(T34A) virus compared to other tumors injected with rAAV-Ctrl virus (Figure 5C). These results indicate that rAAV-Sur-Mut(T34A) virus could mediate long term expression of survivin mutant, inhibit cell proliferation and induce apoptosis in gastric cancer tissues in vivo.

\section{Discussion}

In the present study, we have shown that rAAV-SurMut(T34A) induced apoptosis of gastric cancer both in vitro and in vivo, inhibited tumor growth and enhanced the effects of 5-FU on apoptosis.

Survivin possesses two major functions: inhibiting apoptosis and controlling cell cycle progression [23, 24]. Consistent with anti-apoptotic function of survivin [25], survivin can inhibit apoptosis induced by FasL, Bax, caspase- 3 and -7 overexpression, TNF- $\alpha$, growth factor withdrawal and ultraviolet light $[3,5,10]$. Survivin is highly expressed in G2/M phase and its expression is regulated in a cell cycle dependent manner $[23,24]$. Recent studies have showed that survivin can also upregulate expression of VEGF-C [27] and Mdm2 [28], and activate Aurora-B kinase activity [29]. A recent study has shown that survivin regulates leukemia stem cells through an extensive functional signaling network [30]. The survivininduced expression of target genes and signaling pathways play important roles in cell cycle regulation and apoptosis induction. Our results showed that survivin overexpression promoted cell proliferation of gastric cancer cells, suggesting that survivin is a promising target for gastric cancer therapy.

Previous studies have shown that AAV efficiently transduced colon cancer in vitro and in vivo[23]. In this study, we have demonstrated that AAV could mediate high expression of Sur-Mut(T34A) in gastric cancer cells. Overexpression of Sur-Mut(T34A) inhibited survivin phosphorylation on Thr [34] as determined by Western blotting with a T34A phosphorylation-specific antibody. Functionally, overexpression of Sur-Mut(T34A) resulted in the induction of apoptosis of gastric cancer cells in vitro and in vivo, consistent with previous report that adeonovirus-mediated expression of Sur-Mut(T34A) induced apoptosis and inhibit breast cancer growth.

Chemotherapy is still a major approach for advanced gastric cancer treatment. However, chemotherapeutic drugs resistance is still a problem. Overexpression of survivin has been shown to contribute to drug-resistance [30-32]. Chemotherapeutic drugs inducing G2-M arrest with elevated or residual p34 ${ }^{\mathrm{cdc} 2}$ kinase activity caused $\mathrm{Thr}^{34}$ phosphoralation and increased survivin levels [33]. 5-FU has been shown to induce G2/M arrest in a variety of cell lines and induce apoptosis. In this study, overxpression of Sur-Mut(T34A) enhanced 5-FU-induced cells apoptosis, consistent with previous reports that inhibition of survivin function contributes to overcoming drug-resistance. Accordingly, the expression of Sur-Mut(T34A) mediated by AAV sensitized gastric cancer cells to 5-FU. Our study demonstrated a synergistic effect of the combination of targeting survivin gene therapy and chemotherapy. The combination of targeting survivin with 5-FU deserves further investigation.

In summary, our study shows the therapeutic potential of rAAV mediated Sur-Mut(T34A) in the treatment of gastric cancer, especially in combination with 5-FU intervention. Our results suggest that targeting inhibition of survivin is a potential approach for gastric cancer treatment.

\section{References}

[1] AMBrosini G, ADIDA C, ALTIERI DC. A novel antiapoptosis gene, survivin, expressed in cancer and lymphoma. Nat Med 1997; 3: 917-921. http://dx.doi.org/10.1038/nm0897$\underline{917}$

[2] DEVERAUX QL, REED JC. IAP family proteins--suppressors of apoptosis. Genes Dev 1999; 13: 239-252. http://dx.doi. org/10.1101/gad.13.3.239

[3] KAWASAKI H, TOYODA M, SHINOHARA H, OKUDA J, WATANABE I, et al. Expression of survivin correlates with apoptosis, proliferation, and angiogenesis during human colorectal tumorigenesis. Cancer 2001; 91: 2026-2032. http:// dx.doi.org/10.1002/1097-0142(20010601)91:11<2026::AIDCNCR1228>3.0.CO;2-E

[4] LEE GH, JOO YE, KOH YS, CHUNG IJ, PARK YK, et al. Expression of survivin in gastric cancer and its relationship with tumor angiogenesis. Eur J Gastroenterol Hepatol 2006; 18: 957-963. http://dx.doi.org/10.1097/01. meg.0000230086.83792.56

[5] TAMM I, WANG Y, SAUSVILLE E, SCUDIERO DA, VIGNA $\mathrm{N}$, et al. IAP-family protein survivin inhibits caspase activity and apoptosis induced by Fas (CD95), Bax, caspases, and anticancer drugs. Cancer Res 1998; 58: 5315-520.

[6] WALL NR, O`CONNOR DS, PLESCIA J, POMMIER Y, ALTIERI DC. Suppression of survivin phosphorylation on Thr34 by flavopiridol enhances tumor cell apoptosis. Cancer Res 2003; 63: 230-235.

[7] LING YH, TORNOS C, PEREZ-SOLER R. Phosphorylation of $\mathrm{Bcl}-2$ is a marker of $\mathrm{M}$ phase events and not a determinant 
of apoptosis. J Biol Chem 1998; 273: 18984-18991. http:// dx.doi.org/10.1074/jbc.273.30.18984

[8] ZHAO J, TENEV T, MARTINS LM, DOWNWARD J, LEMOINE NR. The ubiquitin-proteasome pathway regulates survivin degradation in a cell cycle-dependent manner. J Cell Sci 2000; 113 Pt 23: 4363-4371.

[9] YANG Y, FANG S, JENSEN JP, WEISSMAN AM, ASHWELL JD. Ubiquitin protein ligase activity of IAPs and their degradation in proteasomes in response to apoptotic stimuli. Science 2000; 288: 874-877. http://dx.doi.org/10.1126/science.288.5467.874

[10] O'CONNOR DS, GROSSMAN D, PLESCIA J, LI F, ZHANG $\mathrm{H}$, et al. Regulation of apoptosis at cell division by p34cdc2 phosphorylation of survivin. Proc Natl Acad Sci U S A 2000; 97: 13103-107. http://dx.doi.org/10.1073/pnas.240390697

[11] MESRI M, WALL NR, LI J, KIM RW, ALTIERI DC. Cancer gene therapy using a survivin mutant adenovirus. J Clin Invest 2001; 108: 981-990. http://dx.doi.org/10.1172/ LCI200112983

[12] GROSSMAN D, KIM PJ, SCHECHNER JS, ALTIERI DC. Inhibition of melanoma tumor growth in vivo by survivin targeting. Proc Natl Acad Sci U S A 2001; 98: 635-640. http:// dx.doi.org/10.1073/pnas.98.2.635

[13] ASPE JR, WALL NR. Survivin-T34A: molecular mechanism and therapeutic potential. Onco Targets Ther; 3: 247-254.

[14] LI F, LING X. Survivin study: an update of „what is the next wave“? J Cell Physiol 2006; 208: 476-486. http://dx.doi. org/10.1002/jcp.20634

[15] SONG KY, JUNG CK, PARK WS, PARK CH. Expression of the antiapoptosis gene Survivin predicts poor prognosis of stage III gastric adenocarcinoma. Jpn J Clin Oncol 2009; 39: 290-296. http://dx.doi.org/10.1093/jico/hyp020

[16] MIYACHI K, SASAKI K, ONODERA S, TAGUCHI T, NAGAMACHI M, et al. Correlation between survivin mRNA expression and lymph node metastasis in gastric cancer. Gastric Cancer 2003; 6: 217-224. http://dx.doi.org/10.1007/ $\underline{\text { s10120-003-0255-2 }}$

[17] VALLBOHMER D, DREBBER U, SCHNEIDER PM, BALDUS $S$, BOLLSCHWEILER E, et al. Survivin expression in gastric cancer: Association with histomorphological response to neoadjuvant therapy and prognosis. J Surg Oncol 2009; 99: 409-413. http://dx.doi.org/10.1002/jso.21271

[18] TU SP, JIANG XH, LIN MC, CUI JT, YANG Y, et al. Suppression of survivin expression inhibits in vivo tumorigenicity and angiogenesis in gastric cancer. Cancer Res 2003; 63: 77247732 .

[19] WANG TT, QIAN XP, LIU BR. Survivin: potential role in diagnosis, prognosis and targeted therapy of gastric cancer. World J Gastroenterol 2007; 13: 2784-2790.

[20] LI B, FAN J, LIU X, QI R, BO L, et al. Suppression of colorectal tumor growth by regulated survivin targeting. J Mol Med 2006; 84: 1077-1086. http://dx.doi.org/10.1007/s00109-006-0106-9

[21] CARTER PJ, SAMULSKI RJ. Adeno-associated viral vectors as gene delivery vehicles. Int J Mol Med 2000; 6: 17-27.
[22] ENGER PO, THORSEN F, LONNING PE, BJERKVIG R, HOOVER F. Adeno-associated viral vectors penetrate human solid tumor tissue in vivo more effectively than adenoviral vectors. Hum Gene Ther 2002; 13: 1115-1125. http://dx.doi. org/10.1089/104303402753812511

[23] TU SP, CUI JT, LISTON P, HUAJIANG X, XU R, et al. Gene therapy for colon cancer by adeno-associated viral vector-mediated transfer of survivin Cys84Ala mutant. Gastroenterology 2005; 128: 361-375. http://dx.doi.org/10.1053/j. gastro.2004.11.058

[24] O‘CONNOR DS, SCHECHNER JS, ADIDA C, MESRI M, ROTHERMEL AL, et al. Control of apoptosis during angiogenesis by survivin expression in endothelial cells. Am J Pathol 2000; 156: 393-398. http://dx.doi.org/10.1016/S00029440(10)64742-6

[25] MESRI M, MORALES-RUIZ M, ACKERMANN EJ, BENNETT CF, POBER JS, et al. Suppression of vascular endothelial growth factor-mediated endothelial cell protection by survivin targeting. Am J Pathol 2001; 158: 1757-1765. http://dx.doi.org/10.1016/S0002-9440(10)64131-4

[26] TRAN J, RAK J, SHEEHAN C, SAIBIL SD, LACASSE E, et al. Marked induction of the IAP family antiapoptotic proteins survivin and XIAP by VEGF in vascular endothelial cells. Biochem Biophys Res Commun 1999; 264: 781-788. http:// dx.doi.org/10.1006/bbrc.1999.1589

[27] TRAN J, MASTER Z, YU JL, RAK J, DUMONT DJ, et al. A role for survivin in chemoresistance of endothelial cells mediated by VEGF. Proc Natl Acad Sci U S A 2002; 99: 4349-454. http://dx.doi.org/10.1073/pnas.072586399

[28] HARFOUCHE R, HASSESSIAN HM, GUO Y, FAIVRE $\mathrm{V}$, SRIKANT CB, et al. Mechanisms which mediate the antiapoptotic effects of angiopoietin-1 on endothelial cells. Microvasc Res 2002; 64: 135-147. http://dx.doi.org/10.1006/ mvre.2002.2421

[29] PAPAPETROPOULOS A, FULTON D, MAHBOUBI K, KALB RG, O'Connor DS, et al. Angiopoietin-1 inhibits endothelial cell apoptosis via the Akt/survivin pathway. J Biol Chem 2000; 275: 9102-9105. http://dx.doi.org/10.1074/jbc.275.13.9102

[30] ZAFFARONI N, DAIDONE MG. Survivin expression and resistance to anticancer treatments: perspectives for new therapeutic interventions. Drug Resist Updat 2002; 5: 65-72. http://dx.doi.org/10.1016/S1368-7646(02)00049-3

[31] IKEGUCHI M, LIU J, KAIBARA N. Expression of survivin mRNA and protein in gastric cancer cell line (MKN-45) during cisplatin treatment. Apoptosis 2002; 7: 23-29. http:// dx.doi.org/10.1023/A:1013556727182

[32] WANG L, YIN F, DU Y, CHEN B, LIANG S, et al. Depression of MAD2 inhibits apoptosis and increases proliferation and multidrug resistance in gastric cancer cells by regulating the activation of phosphorylated survivin. Tumour Biol; 31: 225-232. http://dx.doi.org/10.1007/s13277-010-0036-6

[33] HAUG K, KRAVIK KL, DE ANGELIS PM. Cellular response to irinotecan in colon cancer cell lines showing differential response to 5-fluorouracil. Anticancer Res 2008; 28: 583-592. 